\title{
Use of $\left[2-{ }^{14} \mathrm{C}\right] \mathrm{Glucose}$ and $\left[5-{ }^{14} \mathrm{C}\right] \mathrm{Glucose}$ for Evaluating the Mechanism and Quantitative Significance of the 'Liver-Cell' Pentose Cycle
}

\author{
John. P. LONGENECKER and John F. WILLIAMS \\ Department of Biochemistry, School of General Studies, Australian National University, \\ Canberra, A.C.T. 2600, Australia
}

(Received 30 October 1979)

\begin{abstract}
1. Expressions are derived for the steady-state measurement of the quantitative contribution of the liver-type pentose phosphate cycle to glucose metabolism by tissues. One method requires the metabolism of $\left[5-{ }^{14} \mathrm{C}\right]$ glucose followed by the isolation and degradation of glucose 6-phosphate. The second procedure involves the metabolism of $\left[2-{ }^{14} \mathrm{C}\right]$ glucose and the isolation and degradation of a triose phosphate derivative, usually lactate or glycerol. 2. Measurements of ${ }^{14} \mathrm{C}$ in $\mathrm{C}-2$ and $\mathrm{C}-5$ of glucose 6-phosphate are required and the values of the $\mathrm{C}-2 / \mathrm{C}-5$ ratios can be used to calculate the quantitative contribution of the L-type pentose cycle in all tissues. 3. The measurement of ${ }^{14} \mathrm{C}$ in $\mathrm{C}-1, \mathrm{C}-2$ and $\mathrm{C}-3$ of triose phosphate derivatives can be used to calculate the quantitative contribution of the L-type pentose cycle relative to glycolysis. 4. The effect of transaldolase and transketolase exchange reactions, reactions of gluconeogenesis and non-oxidative formation of pentose 5-phosphate, isotopic equilibration of triose phosphate pools and isotopic equilibration of fructose 6-phosphate and glucose 6-phosphate, which could interfere with a clear interpretation of the data using $\left[2-{ }^{14} \mathrm{C}\right]-$ and $\left[5-{ }^{14} \mathrm{C}\right]$ glucose are discussed.
\end{abstract}

At least two reaction sequences for the pentose phosphate pathway of glucose metabolism are found in tissues. The first of these, shown in Fig. 1, is the classical pathway (Horecker et al., 1954) which has been detailed in textbooks of general biochemistry since 1956. The second reaction sequence (Fig. 2) was found in liver (Williams \& Clark, 1971, Williams et al., 1978a,b) and some photosynthetic tissues (Clark et al., 1974). The mechanism of the pentose pathway of Fig. 1 has been extensively investigated in rat epididymal fat-tissue (Williams et al., 1974) and it has been established that the pathway of Fig. 1 is the only variant of the pentose cycle found in fat-tissue. For the purposes of the treatments and discussion of this paper the reaction sequence of Fig. 1 is referred to as the fat-cell pathway, or F-type pentose pathway or cycle.

The detailed mechanistic investigations of the pathway shown in Fig. 2 were made with rat and rabbit liver and the results indicated that it was the only reaction sequence of the pentose pathway to be found in liver tissue. The pathway shown in Fig. 2 is thus called the L-type pentose pathway or cycle.

The reactions of Figs. 1 and 2 have the same

Abbreviations used: Gra, glyceraldehyde; Grn, dihydroxyacetone; Xlu, xylulose. overall stoichiometry so that the equation of the pentose pathway by any mechanism is given in reaction (I):

$$
\begin{array}{r}
3 \mathrm{Glc}-6-\mathrm{P}+6 \mathrm{NADP}^{+} \rightarrow 3 \mathrm{CO}_{2}+2 \text { hexose- } 6-P \\
+ \text { triose }-P+6 \mathrm{NADPH}+6 \mathrm{H}^{+}
\end{array}
$$

If the two molecules of hexose 6-phosphate formed by the reactions of the non-oxidative segment of the pathway are equilibrated by glucosephosphate isomerase (EC 5.3.1.9) (reaction II) then the linear pathway becomes cyclic:

$$
2 \text { Hexose } 6-P \rightleftharpoons 2 \text { Glc-6- } P
$$

and is expressed by the sum reaction:

$$
\begin{aligned}
\text { Glc-6-P }+6 \mathrm{NADP}^{+} \rightarrow & 3 \mathrm{CO}_{2}+\text { triose- } P+ \\
& 6 \mathrm{NADPH}+6 \mathrm{H}^{+}
\end{aligned}
$$

Katz, Wood and their co-workers have developed elaborate techniques for quantitatively estimating the contribution of the F-type pentose phosphate cycle to glucose metabolism (Wood \& Katz, 1958; Katz \& Wood, 1960; Wood et al., 1963; Katz \& Wood, 1963; Landau et al., 1964; Katz \& Rognstad, 1967). Basically all the methods involved the mathematical evaluation of the ordered redistribution of the carbon atoms of glucose by reactions of the non-oxidative 


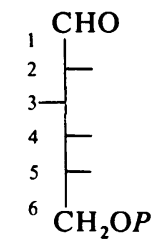

Glucose-6-P

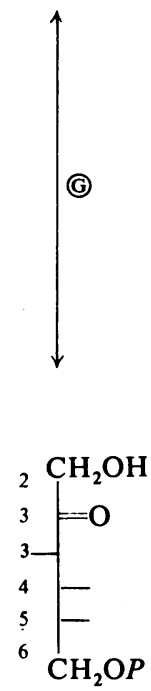

Fructose-6-P

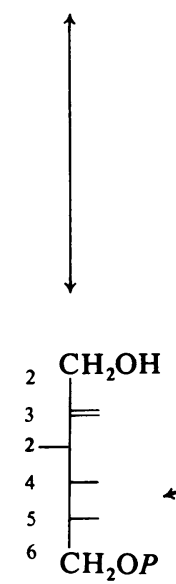

Fructose-6- $P$

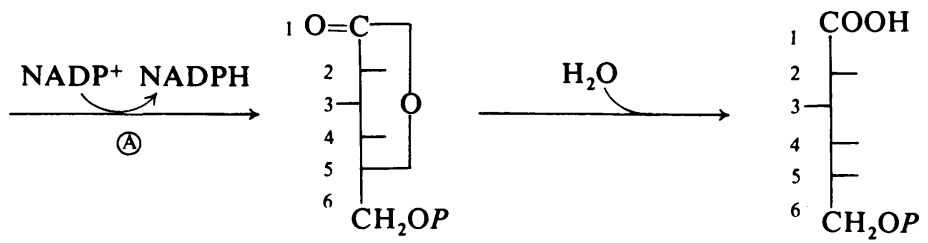

Gluconolactone-6-P

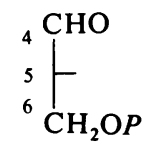

Glyceraldehyde-3-P
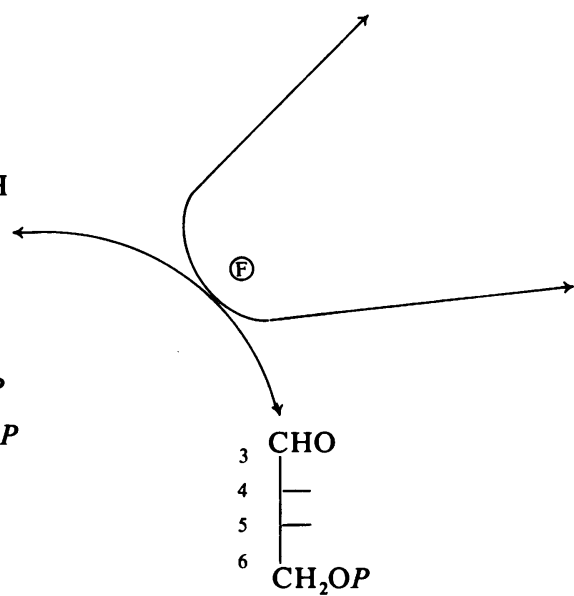

Erythrose-4-P

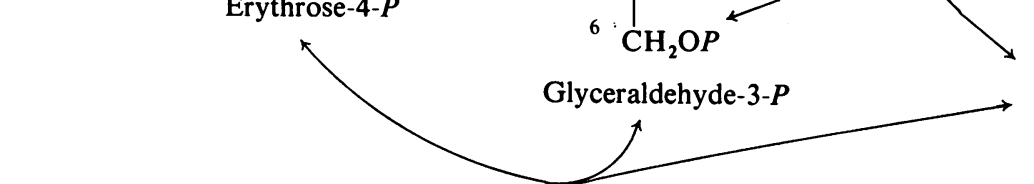

(E)

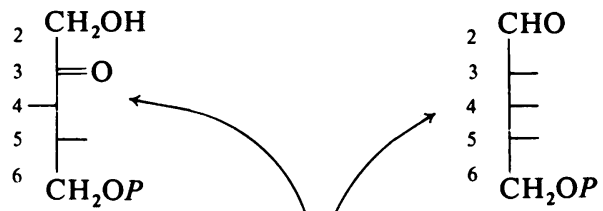

Xylulose-5-P

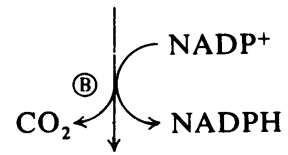<smiles>CC(CO[O+])C(=O)CO</smiles>

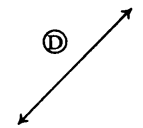

Ribulose-5- $P$

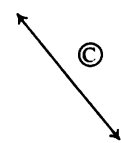

Ribose-5-P

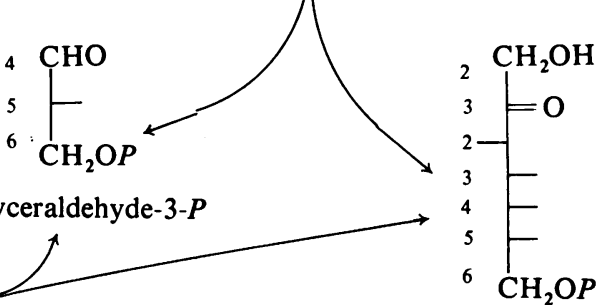

Sedoheptulose-7- $P$

Fig. 1. Reaction sequence of the F-type pentose phosphate cycle

The sequence of reactions comprising the pentose phosphate pathway in adipose tissue as proposed by Horecker $e t$ al. (1954) is shown. The numbers to the left of the structural formulae of each of the intermediates represent the carbon atoms of the substrate glucose. The enzymes involved in the cycle are: (A) glucose 6-phosphate dehydrogenase (EC 1.1.1.49); (B) 6-phosphogluconate dehydrogenase (EC 1.1.1.44); (C) ribose 5-phosphate isomerase (EC 5.3.1.6); (D) ribulose 5-phosphate 3-epimerase (EC 5.1.3.1); (E) transaldolase, (EC 2.2.1.2); (F) transketolase (EC 2.2.1.1); (G) glucosephosphate isomerase. 
segment of the F-type pentose phosphate cycle. Katz \& Wood (1960) used the steady-state ${ }^{14} \mathrm{C}$ labelling pattern generated in glucose 6-phosphate by 'recycling' when $\left[2-{ }^{14} \mathrm{C}\right]-$ or $\left[3-{ }^{14} \mathrm{C}\right]$ glucose is metabolized by the oxidative segment and returned by the non-oxidative pathway, as shown in Fig. 1 . The ${ }^{14} \mathrm{C}$ labelling pattern in glucose 6-phosphate is a consequence of the recycling of fructose 6-phosphate to glucose 6-phosphate. Furthermore, it is evident from reaction (I) that three molecules of glucose 6-phosphate must enter the F-type pentose cycle for every molecule of glucose 6-phosphate that is metabolized to $\mathrm{CO}_{2}$ and triose phosphate.

The inability to reconcile the ${ }^{14} \mathrm{C}$ labelling patterns of hexose 6-phosphate following the metabolism of $\left[2-{ }^{14} \mathrm{C}\right]$ glucose and $\left[1-{ }^{14} \mathrm{C}\right]$ ribose in rabbit liver in vivo (Williams et al., 1971) and in the perfused liver (Schofield et al., 1970) with those of Fig. 1 resulted in the re-investigation of the reaction mechanism of the pentose pathway in liver. These investigations resulted in the formulation of a new reaction sequence for the non-oxidative segment of the pentose phosphate pathway in liver (Williams et al., $1978 a, b)$. This scheme leads to a different steadystate labelling pattern of ${ }^{14} \mathrm{C}$ in hexose 6-phosphate, as illustrated in Fig. 2. The identification of new reactions for the non-oxidative segment of the L-type pentose cycle therefore poses a fundamental question regarding the value of quantitative measurements of the cycle (see Katz, 1961, for a review) in those tissues where there has been no investigation of the mechanism of the non-oxidative reaction segment of the cycle but rather acceptance that the pentose pathway only operated according to the reaction scheme shown in Fig. 1.

The purpose of this paper is to derive theoretical methods for the quantification of the L-type pentose cycle based on the redistribution of the carbon atoms of glucose by their ordered passage through the reactions of Fig. 2. The approach is a modification of that originally used by Katz \& Wood (1960) and which was described in detail by Williams \& Clark (1971). However, the expressions have been derived algebraically using a procedure developed by Landau et al. (1964) and Katz \& Rognstad (1967). The possible effects of any other interfering carbon transfer reactions that could complicate interpretation of patterns of carbon redistribution are also discussed.

\section{Theory}

Distribution of ${ }^{14} \mathrm{C}$ from $\left[5-{ }^{14} \mathrm{C}\right] \mathrm{glucose}$ by reactions of the L-type pentose phosphate cycle

The redistribution of the carbon atoms of glucose by the reactions of the non-oxidative segment of the L-type pentose phosphate cycle is shown in Fig. 2. It is significant that formation of hexose 6-phosphate by these reactions leads to the ordered redistribution of C-4, C-5 and C- 6 of the original glucose molecule into the 'top three' carbons of hexose 6-phosphate. This distribution is unique and distinguishes between the L-type and F-type mechanisms for the non-oxidative segment of the cycle. The estimate is based on the use of $\left[5-{ }^{14} \mathrm{C}\right]$ glucose as substrate and the unique relocation of ${ }^{14} \mathrm{C}$ from $\mathrm{C}-5$ to C-2 of glucose 6-phosphate (Fig. 2). The metabolism of $\left[5-{ }^{14} \mathrm{C}\right]$ glucose by the test tissue is then followed by the isolation and degradation of the glucose moiety of glucose 6-phosphate (Williams et al., 1978a). The distribution of ${ }^{14} \mathrm{C}$ in $\mathrm{C}-2$ of glucose 6-phosphate thus serves as a significant test of the operation of the L-type pentose cycle and as the measure of its relative contribution to total glucose metabolism.

Fig. 2 presents a simplified model showing glucose metabolism via the L-type pentose cycle and the Embden-Meyerhof pathway. The rate of the pentose cycle is designated by $P C$ relative to a net input of substrate glucose. The rate of glucose phosphorylation and the specific radioactivity of substrate glucose have defined values equal to one. The specific radioactivity of any carbon $n$ in glucose or a hexose 6-phosphate is denoted by $H_{n}$ and that of any carbon in triose phosphate by $\operatorname{Tr}_{n}$. In Fig. 2, the numbers to the right of a formula denote the carbon atom in the molecule whereas numbers to the left of the formula denote the origin of the carbon atoms from the original glucose substrate. Because glucose is the only net precursor of hexose 6-phosphate, then, at equilibrium, $H_{n}$ in a system with $\mathrm{C}-n$ labelled glucose must equal that of the C-n position in glucose, i.e., $H_{n}=1$. For the specific radioactivity of C-2 of hexose 6-phosphate $\left(\mathrm{H}_{2}\right)$ the inflow and outflow into the hexose 6-phosphate pool may be written in terms of $\mathrm{H}_{2}$ and $\mathrm{H}_{3}$. The outflow of hexose 6-phosphate can be shown from Fig. 2 to be $H_{2}[3 P C+(1-P C)]$ and the inflow $\mathrm{H}_{2} \mathrm{PC}+\mathrm{H}_{5} \mathrm{PC}$. At steady state, the outflow equals the inflow; i.e.:

$$
\mathrm{H}_{2}[3 P C+(1-P C)]=\mathrm{H}_{5} \mathrm{PC}+\mathrm{H}_{2} P C
$$

Rearrangement gives eqn. (2):

$$
\frac{H_{2}}{H_{5}}=\frac{P C}{1+P C}
$$

Therefore when the pentose cycle equals the inflow, i.e. when $100 \%$ of glucose is metabolized via the pentose cycle, then $P C=1$ and $H_{2} / H_{3}=0.5$. If $P C=0.2$ then $H_{2} / H_{5}=0.167$. In general, by denoting $\mathrm{H}_{2} / \mathrm{H}_{5}$ by the term $r_{\mathrm{H}_{2,5}}$, rearrangement of eqn. (1) gives:

$$
P C=\frac{r_{H_{2,5}}}{1-r_{H_{2,5}}}
$$




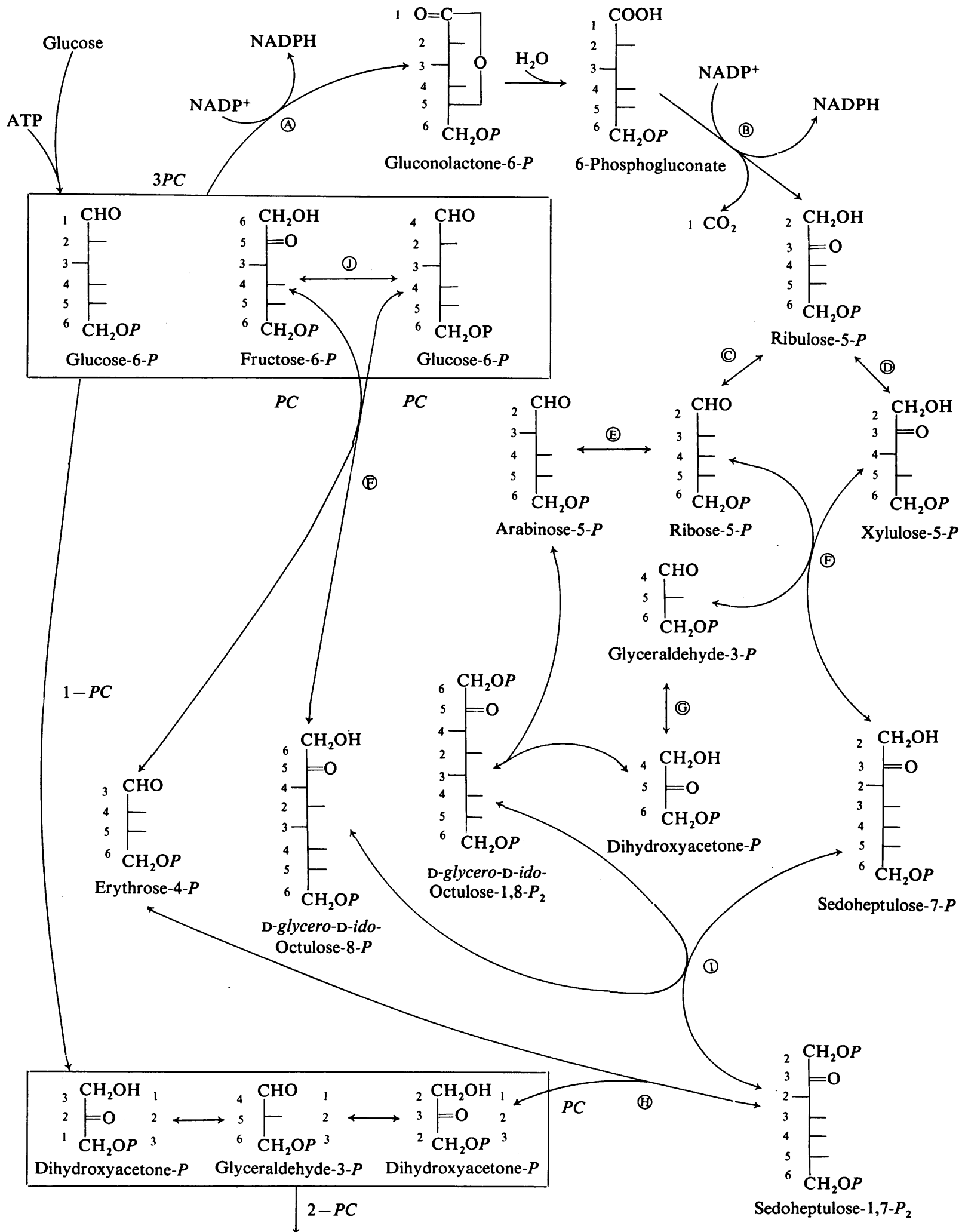


Eqn. (3) yields a value for the pentose cycle relative to total metabolism of glucose including pathways that do not yield triose phosphates (i.e., glycogen synthesis) since no $\operatorname{Tr}_{n}$ terms are required for deviation of this expression.

\section{Equilibration of triose phosphate pools}

The treatment above is based on the assumption that the triose phosphate end-product of one turn of the cycle consists of C-2, C-3 and C-2 of substrate glucose (see Fig. 2). It is an extension of this assumption that the dihydroxyacetone phosphate formed in reaction $\mathrm{G}$ (Fig. 2) and consisting of C-4, C-5 and C- 6 of glucose does not equilibrate with the product triose phosphate, but is compartmented and reacts exclusively with arabinose 5-phosphate in reaction $\mathrm{H}$ of Fig. 2 to form D-glycero-D-idooctulose 1,8-bisphosphate. Equilibration of the two triose phosphate pools of the pentose cycle or their equilibration with the triose phosphates formed via the Embden-Meyerhof pathway would change the isotope-directing predictions of the model and alter the quantitative methods for its measurement.

Evidence supporting the proposal that there is one compartment of dihydroxyacetone phosphate composed of glucose C-4, C-5 and C-6 is shown by (i) the ${ }^{14} \mathrm{C}$ distributions in hexose 6-phosphate formed from $\left[2-{ }^{14} \mathrm{C}\right]$ glucose by isolated hepatocytes (Longenecker \& Williams, 1980); and (ii) the ${ }^{14} \mathrm{C}$ isotope distributions in glucose 6-phosphate formed in vitro from $\left[1{ }^{14} \mathrm{C}\right]$ ribose 5-phosphate by rat liver enzymes (Williams et al., 1978b). If complete equilibration of the triose phosphates occurs, including those formed via the Embden-Meyerhof pathway, then eqn. (3) is no longer valid. In this case, equating the inflow and outflow for $\mathrm{H}_{2}$ yields:

$$
H_{2}(1+2 P C)=H_{2} P C+T_{2} P C
$$

$\mathrm{Tr}_{2}$ can be expressed in terms of $P C$ and the specific radioactivities of $\mathrm{C}-2, \mathrm{C}-5$ and $\mathrm{C}-3$ of hexose, i.e.:

$$
2 \mathrm{Tr}_{2}=\mathrm{H}_{2}(1-P C)+H_{5}(1-P C)+H_{3} P C+H_{5} P C
$$

Inspection of Fig. 2 shows that C-2 or C-5 label cannot appear in C-3 of hexose; hence $H_{3}=0$ and rearrangement of eqn. (5) gives:

$$
\operatorname{Tr}_{2}=\frac{H_{2}(1-P C)+H_{5}}{2}
$$

Substitution of eqn. (6) into eqn. (4) gives:

$$
\frac{H_{2}}{H_{5}}=\frac{P C}{2+P C+P C^{2}}
$$

Eqn. (7) shows that $H_{2} / H_{5}=0.25$ when $P C=1$ and there is complete equilibration of the triose phosphate pools. In the absence of triose phosphate pool equilibration $\mathrm{H}_{2} / \mathrm{H}_{5}=0.5$. Thus, in practice, if triose phosphate pool equilibration was extensive, then use of eqn. (3) would lead to a significant underestimate of the cycle. There is no evidence to support extensive triose phosphate pool equilibration in liver, since L-type pentose cycle values calculated using eqn. (7) yielded unacceptably high $(>80 \%)$ estimates (Longenecker \& Williams, 1980).

\section{Distribution of ${ }^{14} \mathrm{C}$ in triose phosphate following the} metabolism of $\left[2-{ }^{14} \mathrm{C}\right]$ glucose

Fig. 2 shows that metabolism of glucose by the L-type pentose cycle results in unique distributions of carbon atoms in triose phosphate as well as in hexose 6-phosphate. Triose phosphate formed by the aldolase cleavage of sedoheptulose 1,7-bisphosphate (reaction H, Fig. 2) consists of a sequence of C-2, C-3 and C-2 of the original glucose molecules. If $\left[2-{ }^{14} \mathrm{C}\right]$ glucose is used as a substrate, the specific radioactivity of $\mathrm{C}-1, \mathrm{C}-2$ and $\mathrm{C}-3$ of triose phosphates or their derivatives can be used to calculate the extent of the L-type pentose cycle relative to glycolysis. This is so because all triose phosphate formed via the Embden-Meyerhof pathway will contain ${ }^{14} \mathrm{C}$ in $\mathrm{C}-2$ of triose phosphate, whereas that formed by the L-type pentose cycle will contain ${ }^{14} \mathrm{C}$ in $\mathrm{C}-1$ and $\mathrm{C}-3$.

If it is assumed that there is equilibration of the triose phosphates of the Embden-Meyerhof pathway and the product triose phosphate of the pentose cycle, but not the triose phosphate formed by reaction $\mathrm{F}$ of Fig. 2, then the inflow and outflow in

Fig. 2. Redistribution of the carbon atoms of glucose by the L-type pentose phosphate cycle

The sequence of reactions comprising the pentose phosphate cycle in liver as proposed by Williams et al. (1978b) is shown. The carbon atoms of the original glucose are indicated to the left of the structural formulae of each of the intermediates and the numbers to the right of the triose phosphates represent the carbon atom of that molecule. The enzymes involved in the cycle are indicated by the letters and are: (A) glucose 6-phosphate dehydrogenase; (B) 6-phosphogluconate dehydrogenase; (C) ribose 5-phosphate isomerase; (D) ribulose 5-phosphate 3-epimerase; (E) arabinose 5-phosphate epimerase; (F) transketolase; (G) triosephosphate isomerase; (EC 5.3.1.1); (H) aldolase (EC 4.1.2.13); (I) D-glycero D-ido-octulose 1,8-bisphosphate: D-altro-heptulose 7-phosphotransferase; (J) glucosephosphate isomerase.

Vol. 188 
the triose phosphate pool can be expressed for $\operatorname{Tr}_{1}$ as:

$$
T r_{1}(2-P C)=H_{3}(1-P C)+H_{2} P C+H_{4}(1-P C)
$$

Fig. 2 shows that no C-2 label can appear at the C-4 or $\mathrm{C}-3$ positions in hexose 6-phosphate; therefore $H_{3}=H_{4}=0$ and eqn. (8) becomes:

$$
\operatorname{Tr}_{1}=\frac{H_{2} P C}{2-P C}
$$

In terms of $T r_{2}$ the inflow and outflow can be expressed as:

$$
\operatorname{Tr}_{2}(2-P C)=H_{2}(1-P C)+H_{5}(1-P C)+H_{3} P C
$$

Inspection of Fig. 2 shows that $H_{5}=H_{3}=0$; therefore:

$$
\operatorname{Tr}_{2}=\frac{H_{2}(1-P C)}{2-P C}
$$

The ratio of the specific radioactivities of $\mathrm{C}-1$ and $\mathrm{C}-2$ of triose phosphate is given in eqn. (12):

$$
\frac{T r_{1}}{T r_{2}}=\frac{P C}{1-P C}
$$

Denoting $\operatorname{Tr}_{1} / T r_{2}$ as $r_{T_{1,2}}$ then eqn. (12) is expressed as:

$$
P C=\frac{r_{T_{1,2}}}{1+r_{T_{1,2}}}
$$

Eqn. (13) may be used to determine the fraction of glucose metabolism relative to the utilization of glucose via the pentose cycle and Embden-Meyerhof pathway only and assumes that there is no metabolism of glucose by pathways that do not yield triose phosphates (i.e. glycogen synthesis).

It is also obvious from inspection of Fig. 2 that $T r_{1}=T r_{3}$ when $\left[2{ }^{-14} \mathrm{C}\right]$ glucose is substrate. Therefore the distribution of ${ }^{14} \mathrm{C}$ in the carbon atoms of triose phosphate or a derivative such as lactate or glycerol serves as a test of the validity of the reaction sequences of Fig. 2 since $T r_{1} / T r_{3}$ must be unity. It is found that the use of triose phosphate derivatives for quantitation of the L-type pentose cycle are most reliable in non-gluconeogenic tissues, i.e., erythrocytes, chloroplasts, etc. Some limitations of the use of triose phosphate data are discussed by Longenecker \& Williams (1980) for experiments involving measurements of the L-type pentose cycle in isolated hepatocytes.

\section{Assumptions and limitations}

The basic assumption on which all the preceding derivations are based requires that there are no reactions that result in carbon redistributions other than those shown in Fig. 2. Studies of $\left[1-{ }^{14} \mathrm{C} \mid\right.$ ribose 5-phosphate utilization and measurements in vitro of the distribution of ${ }^{14} \mathrm{C}$ into the carbon atoms of hexose 6-phosphate (Williams et al., 1978a) provided much of the evidence for the L-type pentose cycle shown in Fig. 2. These data also clearly indicated the extent of operation of ${ }^{14} \mathrm{C}$ exchange reactions catalysed by the group-transferring enzymes transketolase and transaldolase. The following is an assessment of the effect of these exchange reactions and of the reactions of gluconeogenesis, non-oxidative formation of pentose 5-phosphate, isotopic equilibration of triose phosphate pools and of fructose 6-phosphate with glucose 6-phosphate, which theoretically could act to qualify a clear interpretation of data from experiments using [2$\left.{ }^{14} \mathrm{C}\right]$ - and $\left[5-{ }^{14} \mathrm{C}\right]$ glucose.

\section{Gluconeogenesis from triose phosphate}

Theoretically the reactions of Scheme 1 can introduce ${ }^{14} \mathrm{C}$ from $\mathrm{C}-5$ of glucose into $\mathrm{C}-2$ and C-5 of glucose 6-phosphate. Any significant metabolic activity involving the reaction sequence of Scheme 1 will nullify the value of the theoretical treatments developed above. Such metabolic activity may be expected to occur in liver, and would result in an overestimate of the relative amount of glucose metabolized by the L-type pentose cycle using $\mathrm{H}_{2} / \mathrm{H}_{5}$ ratios in glucose 6-phosphate. The work of Bloom et al. (1955), Cook \& Lorber (1952) and Katz \& Rognstad (1978) indicates that in spite of the potential for glucose synthesis in liver there is very little randomization of ${ }^{14} \mathrm{C}$ from $\left[6-{ }^{14} \mathrm{C}\right]$ - or $\left[1-{ }^{14} \mathrm{C}\right.$ ]glucose into $\mathrm{C}-1$ or $\mathrm{C}-6$ of the glucose units of glycogen (2-4\%). The conclusions of the above workers have been confirmed by Longenecker \& Williams (1980) who showed that there was insignificant transfer of ${ }^{14} \mathrm{C}$ from $\left[4,5,6-{ }^{14} \mathrm{C}\right]$ glucose into $\mathrm{C}-1$ and C-3 of glucose 6-phosphate. It may therefore be concluded that the reactions of gluconeogenesis have little ability to interfere with the ${ }^{14} \mathrm{C}$ redistribution of the $\mathrm{L}$-type pentose cycle. It is suggested that a control incubation using $\left[6-{ }^{14} \mathrm{C}\right]$ - or $\left[4,5,6^{-14} \mathrm{C}\right]$ glucose (Longenecker \& Williams, 1980) should accompany all experiments where the L-type pentose cycle is being measured using $\left[5-{ }^{14} \mathrm{C}\right]$ glucose. In this way an empirical correction can be made for the effect of any contribution of the reactions of Scheme 1.

\section{Reversibility of the non-oxidative segment of the pentose cycle}

Previous methods for estimating the F-type pentose cycle were limited by the assumption that there was no non-oxidative formation of pentose 5-phosphate from hexose 6-phosphate, i.e., that the 
<smiles>C[C@@H](CO)CCCC=O</smiles>

Glc

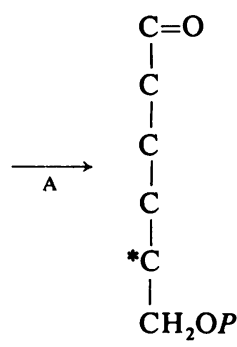

Glc-6-P<smiles>C#CCCC(CO)CC(=O)O</smiles>

Fru-6-P<smiles>O=C(CCCCCO)CO[Pb]</smiles>

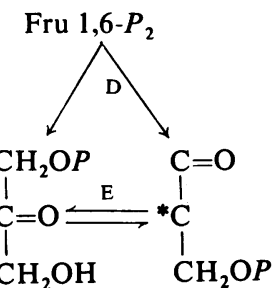

$\left[2-{ }^{14} \mathrm{C}\right] \mathrm{Grn}-P\left[2-{ }^{14} \mathrm{C}\right] \mathrm{Gra}-3-P$<smiles>[B]=C</smiles>

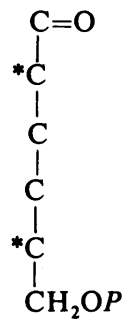<smiles>C=CCCC(CO)CC(=O)O</smiles>

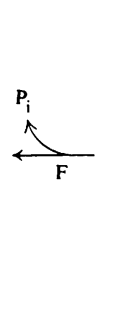<smiles>O=C(CO)CCCCCO</smiles>

\section{$\left[2,5-{ }^{14} \mathrm{C}\right]$ Fru-6- $P$ \\ $12,5-{ }^{14} \mathrm{C} \mid \mathrm{Glc}-6-P$}

Scheme 1. Gluconeogenesis from triose phosphate

Reactions $\mathrm{A}$ to $\mathrm{E}$ involve the phosphorylation of $\left[5-{ }^{-14} \mathrm{C}\right.$ lglucose and reactions of the glycolytic sequence which lead to the aldolase-catalysed condensation of $\left[2-{ }^{14} \mathrm{C}\right]$ glyceraldehyde 3 -phosphate and $\left[2-{ }^{14} \mathrm{C}\right.$ dihydroxyacetone phosphate to form $\left[2,5-{ }^{14} \mathrm{C}\right]$ fructose 1,6 -bisphosphate, the precursor of $\left[2,5-{ }^{14} \mathrm{C} \mid\right.$ glucose 6 -phosphate. A, hexokinase (EC 2.7.1.1); B, Glucose phosphate isomerase; C, phosphofructokinase (EC 2.7.1.11); D, aldolase; E, triosephosphate isomerase; $\mathrm{F}$, fructose 1,6-bisphosphatase (EC 3.1.3.11).

transketolase and transaldolase reactions (Fig. 1) were not reversible. Much evidence, based mainly on the metabolism $\left[1-^{14} \mathrm{C}\right]-,\left[2-{ }^{14} \mathrm{C}\right]-,\left[6^{-14} \mathrm{C}\right]-$ and $\left[\mathrm{U}-{ }^{14} \mathrm{C}\right]$ glucose and incorporations of ${ }^{14} \mathrm{C}$ into pentose phosphate or the pentose moiety of nucleic acid, was interpreted as showing that the transketolase-transaldolase reactions were reversible. Gumaa \& McLean (1969) have estimated that $80 \%$ of pentose 5-phosphate was formed non-oxidatively by Krebs ascites cells. Other studies by Kit $e t$ al. (1957) using lymphatic cells and tumours, Hiatt (1957) using HeLa cells, Schneider \& Potter (1957) with regenerating liver, Schmitz et al. (1954) using Flexner-Jobling carcinoma and rat liver indicated that a significant proportion of the ribose 5-phosphate moiety of nucleic acid was formed nonoxidatively.
There are two mechanisms by which pentose 5-phosphate can be formed non-oxidatively. The first is a reversal of the coupled transketolase-transaldolase reactions shown in Fig. 1. The distribution of the carbon atoms of hexose 6-phosphate and triose phosphate in the resulting pentose 5-phosphate is illustrated by reaction (IV):

$$
2\left\{\begin{array}{l}
H_{1} \\
H_{2} \\
H_{3} \\
H_{4} \\
H_{5} \\
H_{6}
\end{array}+\left\{\begin{array} { l } 
{ \operatorname { T r } _ { 1 } } \\
{ T _ { 2 } } \\
{ T _ { 3 } }
\end{array} \quad \left\{\begin{array} { l } 
{ H _ { 1 } } \\
{ H _ { 2 } } \\
{ T r _ { 1 } } \\
{ T r _ { 2 } } \\
{ T r _ { 3 } }
\end{array} \quad \begin{array} { l } 
{ H _ { 1 } } \\
{ H _ { 2 } } \\
{ H _ { 4 } } \\
{ H _ { 3 } } \\
{ H _ { 6 } }
\end{array} \left\{\begin{array}{l}
H_{3} \\
H_{3} \\
H_{4} \\
H_{5} \\
H_{6}
\end{array}\right.\right.\right.\right.
$$

Vol. 188 
The alternative mechanism involves the reversal of the reactions of the L-type pentose cycle. The distribution of the carbon atoms of hexose 6phosphate and triose phosphate are shown in reaction $(\mathrm{V})$ :

$$
\left\{\begin{array}{l}
H_{1} \\
H_{2} \\
H_{3} \\
H_{4} \\
H_{5} \\
H_{6}
\end{array}+\left\{\begin{array}{l}
H_{1} \\
H_{2} \\
H_{3} \\
H_{4} \\
H_{5} \\
H_{6}
\end{array}+\left\{\begin{array} { l } 
{ T _ { 1 } } \\
{ T _ { 2 } } \\
{ T _ { 3 } }
\end{array} \quad \left\{\begin{array} { l } 
{ H _ { 2 } } \\
{ H _ { 3 } } \\
{ H _ { 4 } } \\
{ H _ { 5 } } \\
{ H _ { 6 } }
\end{array} \quad \left\{\begin{array} { l } 
{ T _ { 1 } } \\
{ T _ { 2 } } \\
{ H _ { 1 } } \\
{ H _ { 2 } } \\
{ H _ { 1 } }
\end{array} \quad \left\{\begin{array}{l}
T_{3} \\
H_{3} \\
H_{4} \\
H_{5} \\
H_{6}
\end{array}\right.\right.\right.\right.\right.\right.
$$

Fru-6- $P+$ Glu-6- $P+$ Grn- $P \rightarrow$ Ara-5- $P+$ Xlu-5- $P+$

Rib-5-P

The formation of pentose 5-phosphate by either of these mechanisms, followed by the metabolism of the resulting pentose 5-phosphate via the mechanism of Fig. 2 results in ${ }^{14} \mathrm{C}$ exchange in the absence of any net metabolism and is referred to as an exchange cycle. The exchange cycles will act to influence the $H_{1} / H_{2}$ and $\operatorname{Tr}_{1} / \operatorname{Tr}_{2}$ ratios and lead to an overestimate or an underestimate respectively of the value of $P C$.

It is significant that operation of reaction (IV) results in the formation of $\left[4-{ }^{14} \mathrm{C}\right]$ pentose 5 -phosphate from $\left[5-{ }^{14} \mathrm{C}\right]$ glucose; therefore the redistribution of ${ }^{14} \mathrm{C}$ in hexose 6-phosphate formed by this exchange cycle cannot be distinguished from true flux of glucose carbon through the complete L-type pentose cycle. Thus the value of $P C$ determined using eqn. (3) represents the sum of this ${ }^{14} \mathrm{C}$ exchange cycle and the L-type pentose cycle. It is possible to qualitatively assess the extent of this exchange independently by using $\left[2-{ }^{14} \mathrm{C}\right]$ glucose as substrate. The pentose 5-phosphate formed via the coupled transketolase-transaldolase reactions from $\left[2-{ }^{14} \mathrm{C}\right.$ ]hexose 6-phosphate will contain ${ }^{14} \mathrm{C}$ in $\mathrm{C}-2$ (reaction IV). When $\left[2-{ }^{14} \mathrm{C}\right]$ pentose 5 -phosphate is metabolized via the L-type pentose cycle, the ${ }^{14} \mathrm{C}$ will be redistributed to C-3 of hexose 6-phosphate. Hence inspection of the ${ }^{14} \mathrm{C}$ distribution in C-3 of hexose 6-phosphate will indicate whether or not this series of ${ }^{14} \mathrm{C}$ exchange reactions is active. Analysis of the ${ }^{14} \mathrm{C}$ distribution in all six carbon atoms of glucose 6-phosphate following the metabolism of $\left[2-{ }^{14} \mathrm{Clglucose}\right.$ by isolated hepatocytes indicates that this series of exchange reactions does not greatly influence the ${ }^{14} \mathrm{C}$ distribution in hexose 6-phosphate (Longenecker \& Williams, 1980; see also Katz \& Rognstadt, 1967).

The operation of the ${ }^{14} \mathrm{C}$ exchange cycle described above will also affect the ${ }^{14} \mathrm{C}$ distribution in derivatives of triose phosphate. The $\left[2-{ }^{14} \mathrm{C}\right]$ pentose 5-phosphate will result in ${ }^{14} \mathrm{C}$ incorporation into $\mathrm{C}-2$ of triose phosphate. Thus operation of the exchange reactions will act to reduce the value of $r_{T_{1,2}}$ and therefore the value of $P C$ calculated from eqn. (13) will be an underestimate of the complete pentose cycle of Fig. 2.

The reversibility of the non-oxidative segment of the L-type pathway results in $a{ }^{14} \mathrm{C}$ distribution that is somewhat more complex. The distribution of ${ }^{14} \mathrm{C}$ from $\left[5-{ }^{14} \mathrm{C}\right]$ hexose 6 -phosphate cannot be distinguished from that following oxidative metabolism of hexose 6-phosphate, except that the specific radioactivity of C-4 of pentose 5-phosphate is diluted by one-third. The complexity arises from the redistribution of $\mathrm{C}-2$ of hexose 6-phosphate, which appears in $\mathrm{C}-1$ and $\mathrm{C}-4$ of pentose 5-phosphate (reaction V). The metabolism of this pentose 5 -phosphate will result in the redistribution of C-2 of the original hexose 6-phosphate into $\mathrm{C}-1$ and $\mathrm{C}-3$ of triose phosphate and $\mathrm{C}-2$ and $\mathrm{C}-5$ of hexose 6-phosphate. Thus ${ }^{14} \mathrm{C}$ in $\mathrm{H}_{2}$ will be lost and a fraction of it will be redistributed into $\mathrm{C}-5$ of hexose 6-phosphate. The resulting $\mathrm{H}_{2} / \mathrm{H}_{5}$ ratio will be perturbed by the operation of these exchange reactions. Theoretically the $\mathrm{H}_{2} / \mathrm{H}_{5}$ ratio following the metabolism of $\left[5-{ }^{14} \mathrm{C}\right]$ glucose will still result in an overestimate of the L-type pentose cycle if reversible exchange of the L-type pathway occurs, since reversibility results in a greater input of ${ }^{14} \mathrm{C}$ from $H_{5}$ into $\mathrm{H}_{2}$ than can be lost from $\mathrm{H}_{2}$. However, the value of $P C$ calculated from eqn. (3) must be less than the sum of pentose cycle flux plus L-type exchange.

Evidence from experiments in vitro using a rat liver enzyme preparation and $\left[1-{ }^{14} \mathrm{C}\right]$ - and [2${ }^{14} \mathrm{C}$ lglucose 6-phosphate indicates that very little pentose 5-phosphate is formed via reversibility of the non-oxidative segment of the L-type pathway. After the metabolism of $\left[1-{ }^{14} \mathrm{C}\right]-$ or $\left[2-{ }^{14} \mathrm{C}\right]$ glucose 6 phosphate and unlabelled fructose 1,6 bisphosphate (as a source of triose phosphate) by the enzymes of rat liver, the pentose 5-phosphates were isolated and the percentage distribution of ${ }^{14} \mathrm{C}$ in each of the carbon atoms of the pentose was determined. When $\left[1{ }^{14} \mathrm{C}\right]$ glucose 6 -phosphate was substrate, $83 \%$ of ${ }^{14} \mathrm{C}$ was found in $\mathrm{C}-1$ of pentose 5 -phosphate and $15 \%$ in $\mathrm{C}-5$. When $\left[2-{ }^{14} \mathrm{C}\right]$ glucose 6 -phosphate was used, $85 \%$ of the ${ }^{14} \mathrm{C}$ was located in $\mathrm{C}-2$ of pentose 5-phosphate with $10 \%$ in C-3 (J. F. Williams and P. F. Blackmore, unpublished work). These results are not consistent with formation of pentose 5-phosphate via the reversal of the L-type pathway, (see reaction $\mathrm{V}$ ) however they are in reasonable agreement with the predicted carbon redistribution via the coupled transketolase-transaldolase reactions (reaction IV).

\section{Transaldolase exchange reaction}

The activity of the reaction sequence involving the transaldolase exchange reaction (Scheme 2) is quite 


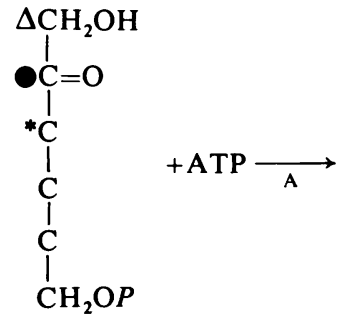

Fru-6- $P$

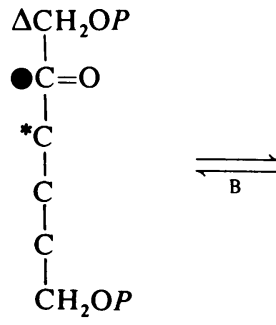

Fru-1,6- $P_{2}$<smiles>O=CCC[OH2+]</smiles>

Grn-P<smiles>O=C(CO)CO</smiles>

Grn- $P$<smiles>C#CCC(C=O)CO</smiles>

Gra-3-P<smiles>O=C(CO)CCCCO</smiles>

Fru-6- $P$<smiles>CC(C=O)CO</smiles>

Gra-3-P<smiles>O=C(CO)C(CCO)CCO</smiles>

Fru-6-P<smiles>O=CCCO</smiles>

Gra-3-P

Scheme 2. Mechanism whereby $C-1, C-2$ and $C-3$ of fructose 6-phosphate are incorporated into C-6, C-5, and C-4 of fructose 6-phosphate by reactions catalysed by $(A)$ phosphofructokinase, $(B)$ aldolase, $(C)$ triosephosphate isomerase and (D) transaldolase exchange

The reaction involving transaldolase exchange also demonstrates how ${ }^{14} \mathrm{C}$ from $\left[5-{ }^{14} \mathrm{C}\right]$ fructose 6 -phosphate would be diluted by incorporation into C-2 of glyceraldehyde 3 -phosphate.

apparent from the degree of ${ }^{14} \mathrm{C}$ labelling of C-5 of hexose 6-phosphate following the metabolism of $12-{ }^{14} \mathrm{C}$ lglucose by isolated hepatocytes (see Table 1 of the following paper, Longenecker \& Williams, 1980). The reactions of Scheme 2 are of apparent concern since they will act to dilute the concentration of ${ }^{14} \mathrm{C}$ in $\mathrm{C}-5$ of hexose 6-phosphate by catalysing its transfer to $\mathrm{C}-2$ of glyceraldehyde 3-phosphate. However, this dilution will have no effect on the $\mathrm{H}_{2} / \mathrm{H}_{5}$ ratio since $\mathrm{Tr}_{2}$ does not appear in eqn. (1); i.e., the value of $P C$ is dependent only on the $\mathrm{H}_{2} / \mathrm{H}_{5}$ ratio at steady state and not on the absolute specific radioactivity of $\mathrm{C}-5$ of hexose 6-phosphate.

It is of interest to note the effect of the transaldolase exchange reaction when $\left[2-{ }^{14} \mathrm{C}\right]$ glucose is substrate. From inspection of Scheme 2 it is seen from reactions $\mathrm{A}, \mathrm{B}$ and $\mathrm{C}$ that $\mathrm{H}_{2}=2 \mathrm{Tr}_{2}$ (assuming that isotopic equilibrium is reached by reaction $\mathrm{C}$ ). Also, when the transaldolase exchange is rapid (reaction D) $H_{5}=T r_{2}$. Thus the $H_{2} / H_{5}$ ratio will be 2 as a consequence of extensive transaldolase exchange when $\left[2-{ }^{14} \mathrm{C}\right]$ glucose is the substrate.

\section{Isotopic equilibration of hexose 6-phosphate}

The theoretical treatment given here requires that there is isotopic equilibrium between fructose 6phosphate and glucose 6-phosphate, i.e., the rate of isotopic equilibration of fructose 6-phosphate with glucose 6-phosphate is very fast relative to the rates of their subsequent metabolism. This stipulation is necessary since the reactions shown in Fig. 2 distribute $\mathrm{C}-5$ of substrate glucose into $\mathrm{C}-2$ of 
fructose 6-phosphate. If isotopic equilibration is incomplete then the measured ratio of the specific radioactivity of $\mathrm{C}-2$ relative to $\mathrm{C}-5$ of glucose 6-phosphate will lead to the underestimation of the quantitative participation of the L-type pentose cycle in total glucose metabolism. Landau et al. (1964) derived expressions for the estimation of the F-type pentose cycle contribution to glucose metabolism by using a model in which no assumption was made as to the extent of isotopic equilibration between glucose 6-phosphate and fructose 6-phosphate. The application of this method to rat adipose tissue demonstrated extensive, but not complete, equilibration and values calculated for the percentage contribution of the pentose cycle to glucose metabolism did not differ greatly from those calculated from methods which assumed complete isotopic equilibrium (Landau \& Katz, 1964). However, Till et al. (1968) found slow equilibration of ${ }^{32} \mathrm{P}$ between glucose 6-phosphate and fructose 6-phosphate in liver and Williams et al. (1971) reported a much higher specific radioactivity of fructose 6-phosphate compared with glucose 6-phosphate after the metabolism of $\left[2-{ }^{14} \mathrm{C}\right]$ glucose by rabbit liver in vivo. These observations suggest that measurements of the L-type pentose cycle in liver using $\left[5-{ }^{14} \mathrm{C}\right] \mathrm{glu}$ cose as substrate and the value of the $\mathrm{H}_{2} / \mathrm{H}_{5}$ ratio in glucose 6-phosphate, together with the assumption of complete equilibration of glucose 6-phosphate and fructose 6-phosphate may underestimate the relative contribution of the cycle to total glucose metabolism.

\section{Conclusions}

The method presented here allows the investigation of the quantitative contribution of the L-type pentose cycle to the glucose metabolism of tissues. Phenomena involving reactions of gluconeogenesis, transaldolase exchange, non-oxidative synthesis of pentose 5-phosphate and non-equilibration of the pool of triose phosphates and hexose 6-phosphate, that can in theory act to qualify the estimation of the L-type pentose cycle in some tissues have been treated.

It is clear that attempts to measure pentose cycle activity in tissues using ${ }^{14} \mathrm{C}$-labelled sugar substrates should not be made until the reaction sequence of the pathway has been investigated. A case has been established for the presence of the L-type pentose cycle in liver (Williams \& Clark, 1971; Williams et al., 1978b) and in photosynthetic tissue (Clark et al., 1974). We have with equal certainly demonstrated that only the F-type pentose cycle occurs in adipose tissue (Williams et al., 1974). To our knowledge no other tissues have been investigated to establish which of these two forms of the pentose cycle are operative, although there is much circumstantial evidence supporting the operation of the L-type pentose cycle in erythrocytes.

In final summary, it is of note that the metabolism of $\left[2-{ }^{14} \mathrm{C}\right]-$ and $\left[5-{ }^{14} \mathrm{C}\right]$ glucose and the distribution of ${ }^{14} \mathrm{C}$ into various positions of glucose 6-phosphate and triose phosphate in tissues not only serves to measure the pathway but affords confirmatory evidence for the operation of the L-type mechanism (see the following paper, Longenecker \& Williams, 1980). In using the procedures presented here for the measurement of the L-type pentose cycle, it is essential that hexose 6-phosphate and triose phosphate intermediates of the cycle should be isolated, purified and degraded for ${ }^{14} \mathrm{C}$ analysis. The use of products of these intermediates that are metabolically distant from the pentose cycle (i.e. glucose units of glycogen instead of glucose 6 . phosphate) is to be avoided since their adoption will only lead to confusion if not the inability to interpret results. This latter note of caution was made clearly by Katz \& Wood (1960).

The work was supported by grants to J. F. W. from the Australian Research Grants Committee and the National Heart Foundation of Australia. J. F. W. gratefully acknowledges a Senior Fulbright Award and a grant from the Wellcome Trust.

\section{References}

Bloom, B., Eisenberg, F. \& Stetten, D. (1955) J. Biol. Chem. 215, 461-466

Clark, M. G., Williams, J. F. \& Blackmore, P. F. (1971) Biochem.J. 125, 381-384

Clark, M. G., Williams, J. F. \& Blackmore, P. F. (1974) Catal. Rev. Sci. Eng. 9, 35-77

Cook, M. \& Lorber, V. (1952) J. Biol. Chem. 199, 1-8

Gumaa, K. A. \& McLean, P. (1969) Biochem. J. 115 , 1009-1029

Hiatt, H. (1957) J. Clin. Invest. 36, 1408-1414

Horecker, B. L., Gibbs, M., Klenoe, H. \& Smyrniotis, P. Z. (1954) J. Biol. Chem. 207, 393-403

Katz, J. (1961) in Radioactive Isotopes in Physiology, Diagnostics and Therapy (Schwiegk, H. \& Turba, F., eds.) pp. 705-721, Springer Verlag, Berlin

Katz, J. \& Rognstad, R. (1967) Biochemistry 6, 22272247

Katz, J. \& Rognstad, R. (1978) Trends Biochem. Sci. 3 171-178

Katz, J. \& Wood, H. G. (1960) J. Biol. Chem. 235, 2165-2177

Katz, J. \& Wood, H. G. (1963) J. Biol. Chem. 238, $517-523$

Kit, S., Klein, J. \& Graham, O. (1957) J. Biol. Chem. 229, 853-863

Landau, B. \& Katz, J. (1964) J. Biol. Chem. 239, 697-704

Landau, B., Bartsch, G., Katz, J. \& Wood, H. G. (1964) J. Biol. Chem. 239, 686-697 
Ljungdahl, L., Wood, H. G., Racker, E. \& Couri, D. (1961) J. Biol. Chem. 236, 1622-1625

Longenecker, J. P. \& Williams, J. F. (1980) Biochem. J. 188, 859-865

Schmitz, H., Potter, V. R. \& Hurlbert, R. B. (1954) Cancer Res. 14, 58-65

Schneider, J. H. \& Potter, V. R. (1957) Cancer Res. 17, 701-706

Schofield, P. J., Gordon, R. B., Clark, M. G. \& Williams, J. F. (1970) Proc. Austr. Biochem. Soc. 3, 31

Till, U., Blume, E., Guenther, J., Reich, J. G., Zahn, D., Klinger, R., Jaroszewicz, K. \& Frunder, H. (1968) Eur.J. Biochem. 6, 373-383

Williams, J. F. \& Clark, M. G. (1971) Search 2, 80-88
Williams, J. F., Rienits, K. G., Schofield, P. J. \& Clark, M. G. (1971) Biochem. J. 123, 923-943

Williams, J. F., Blackmore, P. F. \& Power, P. A. (1974) IRCS Libr. Compend. 2, 1302

Williams, J. F. \& Blackmore, P. F. (1975) Proc. Austr. Biochem. Soc. 8, 29

Williams, J. F., Clark, M. G. \& Blackmore, P. F. (1978a) Biochem. J. 176, 241-256

Williams, J. F., Blackmore, P. F. \& Clark, M. G. (1978b) Biochem. J. 176, 257-282

Wood, H. G. \& Katz, J. (1958) J. Biol. Chem. 233, 1279-1282

Wood, H. G., Katz, J. \& Landau, B. R. (1963) Biochem. Z. 338, 809-847 